\title{
Hematological indices in pediatric patients with acyanotic congenital heart disease: a cross-sectional study of 248 patients
}

\author{
Hanieh Mohammadi', Behzad Mohammadpour Ahranjani ${ }^{2}$, Ehsan Aghaei Moghadam³ ${ }^{3}$ Farzad Kompani ${ }^{4}$,
} Mona Mirbeyk ${ }^{5}$ and Nima Rezaei ${ }^{5,6,7^{*}}$ (1)

\begin{abstract}
Background: Congenital heart disease CHD is a significant cause of mortality and morbidity in children worldwide. Patients with congenital heart disease may develop hematological problems, including thrombocytopenia and neutropenia. In addition, several studies indicate the higher frailty of patients with CHDs to infections and malignancies. Nevertheless, the mechanisms of immune system changes in these patients have remained in the shadow of uncertainty. Moreover, very few studies have worked on cytopenia in CHD. This study has assessed the frequency of thrombocytopenia, neutropenia, lymphopenia, and anemia in pediatric patients with acyanotic congenital heart disease ACHD prior to open-heart surgery.
\end{abstract}

Methods: This cross-sectional study was handled in the Pediatric Cardiology Clinic, Tehran University of Medical Sciences, during pre-operation visits from 2014 till 2019. Two hundred forty-eight children and adolescents with acyanotic congenital heart disease before open-heart surgery met the criteria to enter the study.

Results: A total of 191 (76.7\%) patients with Ventricular Septal Defects (VSD), 37 (14.85\%) patients with Atrial Septal Defects (ASD), and 20 (8.11\%) patients with Patent Ductus Arteriosus (PDA) were enrolled in this study. The median age was 23.87 months. Thrombocytopenia and neutropenia were found, respectively, in 3 (1.2) and 23 (9.2\%) patients. Hemoglobin level and lymphocyte count were significantly lower in patients with neutropenia than patients with normal neutrophil count $(P$ value $=0.024$ and $P$ value $=0.000$ ). Significant positive correlations were found between neutropenia and anemia. There were no correlations between neutrophil count and Platelets. Also, anemia was found in 48 patients (19.3\%). The study also found a statistically significant correlation between the co-existence of VSD and neutropenia in the patients $(P$ value $=0.000$ ).

Conclusion: Although most were mildly neutropenic, there was a significant correlation between neutropenia and Ventricular Septal Defect compared to PDA and ASD groups. Regarding the importance of neutropenia to affect the prognosis of congenital heart defects in infections, it is important to consider further studies on the status of immune system function in these patients.

Keywords: Acyanotic congenital heart disease, Neutropenia, Anemia, Congenital diseases, Pediatrics

*Correspondence: rezaei_nima@yahoo.com

${ }^{5}$ Research Center for Immunodeficiencies, Children's Medical Center, Tehran University of Medical Sciences, Dr Qarib St, Keshavarz Blvd, 14194 Tehran, Iran

Full list of author information is available at the end of the article

\section{Introduction}

Congenital cardiac defects are the most common developmental anomaly, with an incidence of 4 to 10 per 1000 live births. They are the most common noninfectious causes of mortality in pediatrics. CHD unquestionably increases in infants born with Down's 
syndrome, as long as newborns of mothers with diabetes mellitus or mothers with congenital heart defects. Regardless of several explained genetic and epigenetic mechanisms that cause congenital cardiac defects, the pathogenesis of most of them has remained unknown [1-5].

Congenital heart defects are comprised of two main groups based on the presence or absence of cyanosis, including acyanotic congenital heart disease [6] and cyanotic congenital heart disease (CCHD) [7]. Ventricular septal defect (VSD) comprises the most significant percentage of cardiac malformations, up to $40 \%$ of all congenital heart anomalies [8].

There are studies done to screen children with congenital heart diseases [6] for hematologic abnormalities. Laboratory abnormalities of hematologic tests are common in CCHD patients [9]. Erythrocytosis, thrombocytopenia, platelet function defects, coagulation factors deficiencies are the major hematologic disorders in patients with CCHD [10].

Thrombocytopenia, which usually presents as an incidental finding during a routine evaluation, has been identified as a mechanism of the increased incidence of bleeding, thromboembolism [11], and death in hypoxemic CHD patients [12]. In patients with CCHD, platelets are shown to have both qualitative and quantitative abnormalities [13]. However, there are conflicting data regarding the etiology of thrombocytopenia in CCHD [10].

Although anemia in acquired heart disease is a common problem, little is known in patients with CHD [14]. Anemia is an important risk factor to increase morbidity and mortality in patients with CCHD and ACHD [15]. Heart failure in individuals suffering from ACHD may occur and worsen by anemia as comorbidity [16].

The increased risk of infectious diseases and the immune system dysfunction in children with Down's syndrome or infants born from mothers with diabetes mellitus who are at a greater risk of CHD can be assumed as a subtle junction between the reduced immune dysfunction and congenital heart defects $[17,18]$. Moreover, it is not surprising that there are defined chromosomal disorders disturbing both cardiac structure and immune function, such as 22q11.2 deletion syndrome and Jacobsen syndrome [19-21].

Severe congenital neutropenia (SCN) includes different conditions presenting early in infancy, with recurrent and severe infections. Recently, a novel syndrome associating various organ abnormalities, including cardiac defects, urogenital abnormalities, inner ear hearing loss, and congenital neutropenia, has been described, caused by mutations in the glucose-6-phosphatase catalytic subunit 3 (G6PC3) gene [16].
Furthermore, other than what was mentioned, patients with CHD are more predisposed to cardiac infections and complications of other infections such as Intensive Care Unit hospitalization [22, 23].

This study aimed to assess the prevalence of hematologic disorders in pediatric patients with $\mathrm{CHD}$, compare different hematology parameters between non-hypoxemic CHD patients, and evaluate neutropenia frequency, thrombocytopenia, anemia, leukopenia.

\section{Materials and methods Study design}

This cross-sectional study included the hospital records of 248 children and adolescents with $\mathrm{CHD}<18$ years of age, who had attended the Pediatric Cardiology Clinic, Tehran University during pre-operation visits from January 2014 to December 2019 (128 (51.6\%) females and 120 (48.4\%) males; aged 1-168 months, mean 23.87). Informed consent was fulfilled and signed consciously by the guardian of each patient before participation. The Ethical Committee approved the procedures applied in this study of Human Experimentation of Tehran University. The ethical code was IR.TUMS.CHMC. REC.1399.191 and was officially notified on February 1st, 2020.

Exclusion criteria were evident sepsis, septic shock, high fever, localized infections, radical operation due to hypoplastic pulmonary arteries, or increased pulmonary vascular resistance due to Eisenmenger syndrome. Patients with congenital cyanotic heart disease and dysmorphic features/DiGeorge syndrome were excluded. No patient was taking or was known to have taken an antiplatelet or anti-inflammatory agent, and none had either Noonan or Down syndrome, in which thrombocytopenia occasionally occurs. None had abnormal liver function tests or hepatosplenomegaly. No platelet transfusion, packed red cells was given prior to hematological analysis. Patients were divided into two groups according to the neutrophil count; ACHD with neutropenia (neutrophil count $<1500 \times 10^{9} / \mathrm{L}$ ) and ACHD with normal neutrophil count (neutrophil count $\geq 1500 \times 10^{9} / \mathrm{L}$ ). This cutoff to diagnose neutropenia is commonly used by physicians in clinics worldwide [24-26]. Patients in neutropenic groups were also divided into three groups according to the severity of neutropenia; mild neutropenia (neutrophil count $<1500 \times 10^{9} / \mathrm{L}$ ), moderate neutropenia (neutrophil count $<1000 \times 10^{9} / \mathrm{L}$ ) and severe neutropenia (neutrophil count $<500 \times 10^{9} / \mathrm{L}$ ). Also, another hematological profile of ACHD patients according to their disease was determined (Table 2). Thrombocytopenia was defined as platelet count $<150 \times 10^{9} / \mathrm{L}$. According to patient age, we also assumed anemia as HB less than 2SD [27, 28]. Our investigations from the patients' hospital records carried 
out their sex, age at the pre-operation time, echocardiographic data that approved the diagnosis of CHD, and their registered hematological profile one day before cardiac surgery.

\section{Sample collection and laboratory investigations used in the hospital}

Peripheral blood samples were gathered on potassiumethylene diamine tetra acetic acid (K2-EDTA) $(1.2 \mathrm{mg} /$ $\mathrm{mL}$ ) for complete blood count (CBC). For chemical analysis, clotted samples were obtained, and serum was separated by centrifugation for $15 \mathrm{~min}$ at $1000 \times g$. CBC was performed using SysmexXt 2000i. A qualitative examination of $\mathrm{C}$-reactive protein with latex agglutination test had been done to see whether the patients had an acute infection or not.

\section{Echocardiography}

All patients underwent an echocardiographic study using a Philips iE33 machine. A standard 2D echocardiogram was done for all patients enrolled in the study using phased array transducers of different frequencies tailored according to each patient's age, body built, and weight.

\section{Statistical analysis}

The gathered data were analyzed applying Statistical Program for Social Science version 26. Quantitative variables were defined as mean and standard deviation or median and interquartile range (IQR: the difference between 25 and 75th percentiles). Shapiro-Wilk test was employed to determine the normality of data distribution. Qualitative variables were described as number and percent. In order to analyze parametric quantitative variables, a Student $t$ test was performed. The Mann-Whitney test was employed to statistically compare nonparametric quantitative measures between two groups. A $P$ value $<0.05$ was considered significant in all analyses.

\section{Results}

Clinical and laboratory characteristics of the ACHD patients Two hundred forty-eight patients, including 120 (48.4\%) male and 128 (51.6\%) female that met the criteria to enter the study, were categorized into three main subgroups according to their diagnosis based on an echocardiographic study: 191 (77\%) patients with Ventricular septal defect (VSD), 37 (14.9\%) patients with Atrial septal defect (ASD), And 20 (8.1\%) with Patent Ductus arteriosus (PDA). We categorized the patients according to their principal diagnosis, which means to avoid duplicating the data if the patient had the combination of VSD and any other cardiac anomaly including PDA or VSD, we consider it in the VSD group. Moreover, the patients with ASD + PDA were categorized in the ASD group. The patients' age ranged from 1 to 168 months with a mean age of 23.9 months. The demographic data and hematologic profile of patients are shown in Table 1.

None had abnormal liver function tests or hepatosplenomegaly. None of the patients complained of overt bleeding manifestations. Anemia was the most frequent, including $19.3 \%$ of patients, followed by neutropenia with $9.3 \%$ of all patients; leukopenia and thrombocytopenia were the least frequent.w

Table 1 Clinical data and Hematological profile of ACHD patients with neutropenia compared with a normal Neutrophil count

\begin{tabular}{|c|c|c|c|c|}
\hline Variables & $\begin{array}{l}\text { Patients with ACHD } \\
\text { neutropenia }(n=23)\end{array}$ & $\begin{array}{l}\text { Patients with ACHD Normal } \\
\text { Neutrophil count }(n=225)\end{array}$ & Total & $P$ value \\
\hline Age (months), Median (IQR) & $7(11)$ & $11(22)$ & $10(19)$ & 0.06 \\
\hline Weight (Kg), Median (IQR) & $6(5.3)$ & $7(6)$ & $6.8(6)$ & 0.66 \\
\hline Sex, $n(\%)$ & & & & 0.7 \\
\hline Male & $12(52.2)$ & $108(48)$ & $120(48.4)$ & \\
\hline Female & $11(47.8)$ & $117(52)$ & $128(51.6)$ & \\
\hline Type of CHD, $n(\%)$ & & & & $0.015^{*}$ \\
\hline VSD & $22(95.6)$ & $169(75.1)$ & $191(77)$ & $0.000^{*}$ \\
\hline ASD & $0(0)$ & $37(16.4)$ & $37(14.9)$ & $0.000^{*}$ \\
\hline PDA & $1(4.4)$ & $19(8.4)$ & $20(8.1)$ & 0.49 \\
\hline WBC count $\left(\times 10^{9} / \mathrm{L}\right)$, Mean (SD) & $7.6(2.1)$ & $10.3(3.6)$ & $10.1(3.6)$ & $0.000^{*}$ \\
\hline Hemoglobin (g/dL), Mean (SD) & $11.1(1.5)$ & $11.9(1.5)$ & $11.8(1.5)$ & $0.005^{*}$ \\
\hline Platelet count $\left(\times 10^{9} / \mathrm{L}\right)$, Mean $(\mathrm{SD})$ & $328(103)$ & $325(102)$ & $325.6(102)$ & 0.89 \\
\hline Anemia, $n(\%)$ & $12(52.2)$ & $36(16)$ & $48(19.3)$ & $0.000^{*}$ \\
\hline Leukopenia, $n(\%)$ & $2(8.1)$ & $1(0.4)$ & $3(1.2)$ & 0.184 \\
\hline Thrombocytopenia, $n$ (\%) & $0(0)$ & $3(1.3)$ & $3(1.2)$ & 0.74 \\
\hline
\end{tabular}




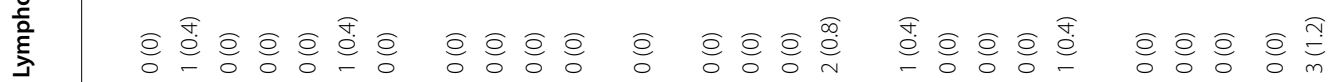

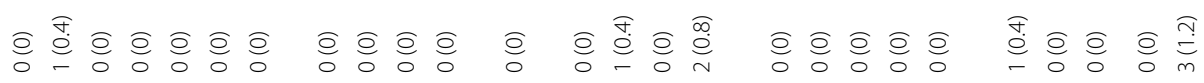

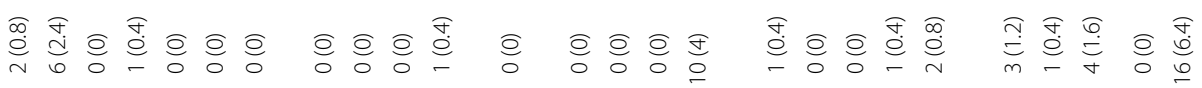

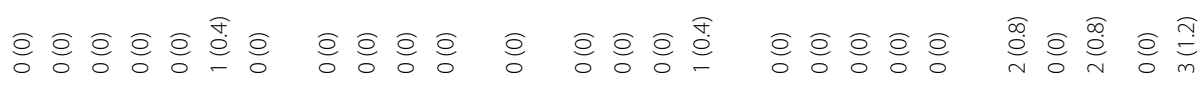

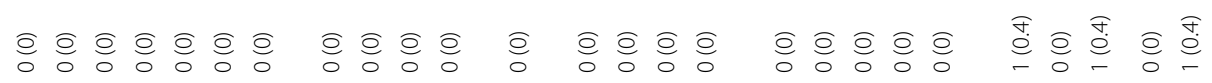

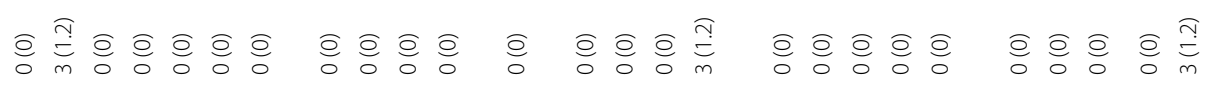
(1)

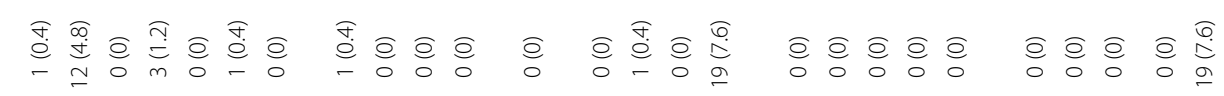

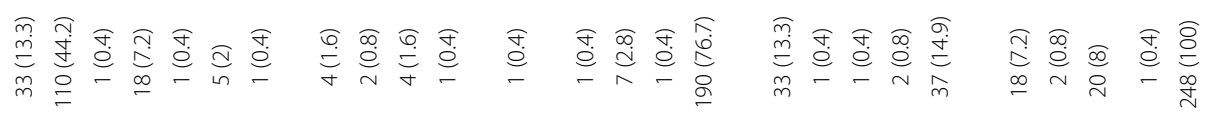


Table 3 Correlations of hematologic profile in three major categories of heart defects

\begin{tabular}{|c|c|c|c|c|c|}
\hline & Frequency & VSD & ASD & PDA & $P$ value \\
\hline \multicolumn{6}{|l|}{ Neutropenia, n (\%) } \\
\hline Mild Neutropenia & $19(7.6)$ & $19(7.6)$ & $0(0)$ & $0(0)$ & $0.005^{*}$ \\
\hline Moderate Neutropenia & $3(1.2)$ & $3(1.2)$ & $0(0)$ & $0(0)$ & \\
\hline Severe neutropenia & $1(0.4)$ & $0(0)$ & $0(0)$ & $1(0.4)$ & \\
\hline Thrombocytopenia, $n$ (\%) & $3(1.2)$ & $1(0.4)$ & $0(0)$ & $2(0.8)$ & $0.001^{*}$ \\
\hline Thrombocytosis, n (\%) & $16(6.4)$ & $10(4)$ & $2(0.8)$ & $4(1.6)$ & $0.037^{*}$ \\
\hline Anemia, $n(\%)$ & $48(19.3)$ & $37(14.9)$ & $8(3.2)$ & $3(1.2)$ & 0.83 \\
\hline Leukopenia, n (\%) & $3(1.2)$ & $2(0.8)$ & $0(0)$ & $1(0.4)$ & 0.23 \\
\hline Lymphopenia, $n$ (\%) & $3(1.2)$ & $2(0.8)$ & $1(0.4)$ & $0(0)$ & 0.61 \\
\hline $\mathrm{Hb}$ (gr/dL), Mean & $11.8(1.5)$ & $11.8(1.4)$ & $12.3(1.9)$ & $11.6(1.8)$ & 0.1 \\
\hline Platelet count $\left(\times 10^{9} / \mathrm{L}\right)$, Mean & $325.6(102)$ & $322(93)$ & $336(129)$ & $325(102)$ & 0.8 \\
\hline WBC count $\left(\times 10^{9} / \mathrm{L}\right)$, Mean & $10.1(3.6)$ & $9.9(3.6)$ & $10(3.4)$ & $11.3(3.9)$ & 0.21 \\
\hline Lymphocyte count $\left(\times 10^{9} / L\right)$, Mean & $5.5(2.4)$ & $5.5(2.4)$ & $4.9(2.2)$ & $6(2.7)$ & 0.33 \\
\hline Neutrophil count $\left(\times 10^{9} / \mathrm{L}\right)$, Mean & $3.4(2.2)$ & $3.2(2.3)$ & $3.9(2.1)$ & $3.7(1.8)$ & $0.018^{* *}$ \\
\hline
\end{tabular}

*Pearson Chi-Square asymptotic significance

**Kruskal-Wallis test asymptotic significance

This study also scrutinized the hematologic profile status, including neutropenia (mild, moderate, and severe), Thrombocytopenia, Anemia, Leukopenia, Lymphopenia, Thrombocytosis in the context of detailed cardiologic diagnosis patients (Table2).

There were fourteen groups of VSD patients with comalformations of the heart besides those with single VSD. The most frequent disease was the combination of VSD and pulmonary hypertension [3], comprised of 110 patients $(44.2 \%)$, followed by 33 VSD patients (13.3\%).

The comparison of the hematologic profile between three VSD, ASD, and PDA groups is shown in Table3.

\section{Neutropenia among patients with ACHD}

The patients have been divided into two groups regarding neutrophil count; 23 (9.3\%) patients with neutropenia and $225(90.7 \%)$ patients with a normal neutrophil count.

There was no significant difference between two groups of neutropenic and non-neutropenic patients regarding age $(P$ value $=0.06)$, gender $(P$ value $=0.7)$, and weight $(P$ value $=0.66)$.

Twenty-two out of 23 neutropenic patients suffered from VSD, which comprised $11.5 \%$ of total VSD patients $(P$ value $=0.000)$. In other words, the frequency of neutropenia was reported significantly more in the VSD group than non-VSD groups and significantly less in the ASD group compared to the rest of the patients, while it was not correlated with PDA.

Additionally, the Mann-Whitney $U$ test was employed to examine whether the mean ANC differs in VSD patients from patients without VSD. The mean ANC in the VSD group was meaningfully less than that in the non-VSD group ( $P$ value $=0.005)$.

Furthermore, other hematologic features that were assessed between two groups of neutropenic and nonneutropenic patients are presented in Table 1.

Although neutropenia frequency was higher in VSD patients than those without VSD, most of them were mild ( $P$ value $=0.029)$. This study also cross-tabulated three major heart defect types with neutropenia severity in four categories: normal neutrophil count, mild, moderate, and severe neutropenia. The Pearson's chi-square asymptotic significance was obtained as equal as 0.005 , which means the severity of neutropenia correlates significantly with the type of heart defect. (Table3).

\section{Hematologic abnormalities among patients with ACHD}

In this study, among all patients, 48 (\%19.3) patients had $\mathrm{Hb}<2 \mathrm{SD}$ for their age (mean $11.81 \pm 1.6$ ), which was not correlated with the type of the CHD $(P$ value $=0.83)$. The mean amount of $\mathrm{Hb}$ was $11.8 \pm 1.4,12.6 \pm 1.9$, and $11.6 \pm 1.8$ among patients with VSD, ASD, and PDA, respectively $(P$ value $=0.1)$.

We also evaluated thrombocytosis in patients with ACHD, defined as platelet count $\geq 450 \times 10^{9} / \mathrm{L}$. Thrombocytosis was presented in 16 (6.4\%) of the screened patients. Thrombocytopenia was only seen in three patients, including one patient with a combination of VSD-PDA and two with PDA, which means all of these three were suffering from PDA. The mean platelet count was not different between the three groups of $\mathrm{CHDs}$ (Table 3). 


\section{Discussion}

CHD prevalence has increased over the past three decades due to technological advancement and medical care, diagnosis, and management, while about 12 million people with CHD are now living worldwide [29].

CHD led to a considerable burden on patients' health, society, and economics as long as imposing 589,479 years lived with disability, in 2017 [30].

Over time, with the increase in life expectancy of CHD patients, its mortality has decreased and slightly has been shifting to non-cardiac reasons, such as infection or malignancies [31-33].

A nationwide population study in Taiwan from 2000 to 2014 has shown that more than half of the causes of death in adults with ACHD are non-cardiac, as well as the results of the nationwide study by $\mathrm{Yu}$ et al. in Australia [33, 34]. Naidu et al. reported infection as the leading cause of non-cardiac deaths accounting for $10 \%$ of CHD mortality from 1991 to 2015 [35]. Diller et al. has shown that in pneumonia patients who need hospitalization, the co-existence of CHD plays a crucial role in increasing the risk of death and adverse events such as demanding mechanical ventilation [36].

Numerous studies have indicated that viral respiratory infections, including influenza and COVID-19, impose a higher risk of mortality, a longer duration of hospitalization, and more complications and economic costs in patients with CHD than the general population [6, 37-39].

The fact that CHD patients are frailer to infections and malignancies gives a cue that the immune system should be studied more in these patients, especially as the world is struggling with the COVID-19 pandemic [40]. Neutrophils and lymphocytes are essential parts of innate and adaptive immune systems. Interestingly, mutations in some genes such as Notch signaling genes or Ras/mitogen-activated protein kinase signaling genes involved in neutrophil functions have led to heart defects in mice [40]. However, unfortunately, the data about how the development of the immune system mutates in CHD are plainly scarce.

In a very recent study by Sarwar et al. assessing the hematological profile of VSD patients, 33.3\% of VSD patients aged between 4 and 5 years had lower counts of WBC count; however, the mentioned study did not evaluate the neutrophil count [41]. Reduced T lymphocyte cell and B lymphocyte cell levels have also been reported in the literature in the past decades [42, 43].

In our study, 9.2 percent of patients had neutropenia. Unfortunately, we did not assess a control group, but considering the prevalence of neutropenia in children in Iran, accounting for $3 \%$, it seems that neutropenia is more common in CHD patients [44].
Comparing the CHD group with neutropenia against those without neutropenia, anemia was more common as long as $\mathrm{HB}$ amount and WBC count were significantly lower.

Moreover, neutropenia was significantly more common in patients with ventricular defects compared with the non-VSD group. Our findings suggest that these alterations may emanate from a solitary developmental confounding factor. Some factors may regulate ventricular formation, hematological development, and neutrophil production or activation during the embryonic period.

Coagulopathy is another issue that may complicate CHD with an increased risk for both bleeding and thrombotic complications [45, 46]. Moreover, its mechanisms include abnormal blood flow, endothelial dysfunction, reduced coagulation factors, low platelet count or function, fibrinolysis. Furthermore, low platelet count can put CHD patients at higher risk of death [47]. Previous studies demonstrated that platelet count in patients with cyanotic CHD tends to decrease and develop thrombocytopenia [48]. In a study published by Lill et al. in 2006, the frequency of thrombocytopenia in 105 patients with cyanotic CHD was $25 \%$ with an average count of $155 \pm 12 \times 10^{9} / \mathrm{L}$ [48]. In another study by Jensen et al., the mean platelet count of $98 \mathrm{CCHD}$ patients was determined $159 \pm 60 \times 10^{9} / \mathrm{L}$ [49]

In this study, the frequency of thrombocytopenia and thrombocytosis was $1.3 \%$ and $6.4 \%$, respectively. This contrast of thrombocytopenia frequency may be because this study assessed acyanotic CHD patients, while previous ones had done with CCHD patients. This study may suggest that thrombocytopenia is not the main problem of these patients, while other hematologic anomalies such as anemia and neutropenia should be more focused on.

Patients suffering from cardiac diseases are frequently reported with anemia, which is highly prevalent without vitamin or mineral insufficiency or other definable reasons [50]. However, it was emphasized that more than one-third of the patients with CCHD had iron deficiency anemia [51], which may have been aggravated by concomitant disorders or a combination of factors $[15,52]$.

Studies were clear that preoperative anemia, especially in heart diseases, gives rise to postoperative cardiac events, complications, and death [53].

Our study noticed that a remarkable number of patients with ACHD had anemia preoperatively, approving the study performed by Amoozgar et al., in which half of ACHD patients were anemic and undiagnosed due to being asymptomatic [54]. Besides, in the recent study by Sarwar et al., the prevalence of anemia with below-normal hemoglobin varied from 30 to 40 percent in different 
age groups from 0 to 36 months [41]. It is essential to assess and treat preoperative anemia regarding the significant frequency of anemia in these patients and prevent its complications, morbidity, and mortality. Indeed, physicians commonly misdiagnose anemia because it is often asymptomatic or exhibits largely nonspecific symptoms.

In conclusion, ACHD patients, especially patients with VSD, should be considered a group with a potential risk of neutropenia and be evaluated to avoid remaining misdiagnosed as well as to reduce the risk of infection and its consequences. Besides, this study highly suggests further evaluation to determine the frequency and complications of neutropenia and other hematological impairments in ACHD patients, affecting their prognosis. Finally, future studies should examine the cellular and molecular basis of immune system dysfunction in CHD to pave the way for the health care system to provide these patients an improved quality of life.

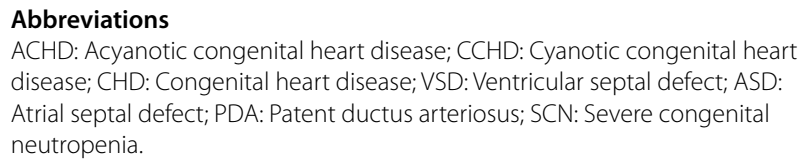

Abbreviations

ACHD: Acyanotic congenital heart disease; CCHD: Cyanotic congenital heart disease; CHD: Congenital heart disease; VSD: Ventricular septal defect; ASD: Atrial septal defect; PDA: Patent ductus arteriosus; SCN: Severe congenital neutropenia.

\section{Acknowledgements}

Not applicable.

\section{Authors' contributions}

HM was responsible for gaining ethical approval, gathering samples and data, and writing primary draft. NR, BMA, EAM, and FK contributed in the design, developing protocol, and supervising the work. MM was responsible for data analysis and manuscript drafting. All authors read and approved the final manuscript.

\section{Funding}

This study has not received any funding from any institutions.

\section{Availability of data and materials}

The datasets used or analyzed during the current study are available from the corresponding author on reasonable request.

\section{Declarations}

\section{Ethics approval and consent to participate}

The Ethical Committee approved the procedures applied in this study of Human Experimentation of Tehran University (Ethics Approval Code: IR.TUMS. CHMC.REC.1399.191). Informed consent was fulfilled and signed consciously by the guardian of each patient before participation.

\section{Consent for publication}

Not applicable.

\section{Competing interests}

All of the authors of this paper have no conflicts of interest, including specific financial interests, relationships, and/or affiliations relevant to the subject matter or materials included.

\section{Author details}

${ }^{1}$ Resident Research Committee, Children's Medical Center, Pediatrics Center of Excellence, Tehran University of Medical Sciences, Tehran, Iran. ${ }^{2}$ Department of Pediatric Cardiology, Bahrami Children's Hospital, Tehran University of Medical Sciences, Tehran, Iran. ${ }^{3}$ Pediatric Department, Children Medical Center,
Pediatric and Adolescent Cardiovascular Research Center, Tehran University of Medical Sciences, Tehran, Iran. ${ }^{4}$ Division of Hematology and Oncology, Children's Medical Center, Pediatrics Center of Excellence, Tehran University of Medical Sciences, Tehran, Iran. ${ }^{5}$ Research Center for Immunodeficiencies, Children's Medical Center, Tehran University of Medical Sciences, Dr Qarib St, Keshavarz Blvd, 14194 Tehran, Iran. ${ }^{6}$ Department of Immunology, School of Medicine, Tehran University of Medical Sciences, Tehran, Iran. ${ }^{7}$ Network of Immunity in Infection, Malignancy and Autoimmunity (NIIMA), Universal Scientific Education and Research Network (USERN), Tehran, Iran.

Received: 1 October 2021 Accepted: 30 January 2022

Published online: 08 March 2022

\section{References}

1. Hoffman Jl, Kaplan S (2002) The incidence of congenital heart disease. J Am Coll Cardiol 39(12):1890-1900. https://doi.org/10.1016/s07351097(02)01886-7

2. Mitchell SC, Korones SB, Berendes HW (1971) Congenital heart disease in 56,109 births. Incid Nat Hist Circ 43(3):323-332. https://doi.org/10.1161/ 01.cir.43.3.323

3. Mitchell SC, Sellmann AH, Westphal MC, Park J (1971) Etiologic correlates in a study of congenital heart disease in 56,109 births. Am J Cardiol 28(6):653-657. https://doi.org/10.1016/0002-9149(71)90053-1

4. Martin GR, Perry LW, Ferencz C (1989) Increased prevalence of ventricular septal defect: epidemic or improved diagnosis. Pediatrics 83(2):200-203

5. van der Linde D, Konings EE, Slager MA, Witsenburg M, Helbing WA, Takkenberg JJ et al (2011) Birth prevalence of congenital heart disease worldwide: a systematic review and meta-analysis. J Am Coll Cardiol 58(21):2241-2247. https://doi.org/10.1016/j.jacc.2011.08.025

6. Sachdeva S, Ramakrishnan S, Choubey M, Koneti NR, Mani K, Bakhru S et al (2021) Outcome of COVID-19-positive children with heart disease and grown-ups with congenital heart disease: a multicentric study from India. Ann Pediatr Cardiol 14(3):269-277. https://doi.org/10.4103/apc. apc_134_21

7. Sadowski SL (2009) Congenital cardiac disease in the newborn infant: past, present, and future. Crit Care Nurs Clin N Am 21(1):37-48, vi. https:// doi.org/10.1016/j.ccell.2008.10.001

8. Penny DJ, Vick GW 3rd (2011) Ventricular septal defect. Lancet 377(9771):1103-1112. https://doi.org/10.1016/s0140-6736(10)61339-6

9. Goel M, Shome DK, Singh ZN, Bhattacharjee J, Khalil A (2000) Haemostatic changes in children with cyanotic and acyanotic congenital heart disease. Indian Heart J 52(5):559-563

10. Zabala LM, Guzzetta NA (2015) Cyanotic congenital heart disease (CCHD): focus on hypoxemia, secondary erythrocytosis, and coagulation alterations. Paediatr Anaesth 25(10):981-989. https://doi.org/10.1111/pan. 12705

11. Kajimoto $H$, Nakazawa M, Murasaki K, Mori Y, Tanoue $K$, Kasanuki H et al (2007) Increased thrombogenesity in patients with cyanotic congenital heart disease. Circ J 71(6):948-953. https://doi.org/10.1253/circj.71.948

12. Martínez-Quintana E, Rodríguez-González F (2015) Thrombocytopenia in congenital heart disease patients. Platelets 26(5):432-436. https://doi. org/10.3109/09537104.2014.925104

13. Auluck A, Manohar C (2006) Haematological considerations in patients with cyanotic congenital heart disease: a review. Dent Update 33(10):617-8, 20-2. https://doi.org/10.12968/denu.2006.33.10.617

14. Collins N, Piran S, Harrison J, Azevedo E, Oechslin E, Silversides CK (2008) Prevalence and determinants of anemia in adults with complex congenital heart disease and ventricular dysfunction (Subaortic right ventricle and single ventricle physiology). Am J Cardiol 102(5):625-628. https://doi. org/10.1016/j.amjcard.2008.04.034

15. Ootaki Y, Yamaguchi M, Yoshimura N, Oka S, Yoshida M, Hasegawa T (2007) The efficacy of preoperative administration of a single dose of recombinant human erythropoietin in pediatric cardiac surgery. Heart Surg Forum 10(2):E115-E119. https://doi.org/10.1532/hsf98.20061183

16. Felker GM, Shaw LK, Stough WG, O'Connor CM (2006) Anemia in patients with heart failure and preserved systolic function. Am Heart J 151(2):457-462 
17. Ram G, Chinen J (2011) Infections and immunodeficiency in Down syndrome. Clin Exp Immunol 164(1):9-16. https://doi.org/10.1111/j.13652249.2011.04335.x

18. Opara PI, Jaja T, Onubogu UC (2010) Morbidity and mortality amongst infants of diabetic mothers admitted into a special care baby unit in Port Harcourt, Nigeria. Ital J Pediatr 36(1):77. https://doi.org/10.1186/ 1824-7288-36-77

19 Morsheimer M, Brown Whitehorn TF, Heimall J, Sullivan KE (2017) The immune deficiency of chromosome 22q11.2 deletion syndrome. Am J Med Genet A. 173(9):2366-72. https://doi.org/10.1002/ajmg.a.38319

20. Tootleman E, Malamut B, Akshoomoff N, Mattson SN, Hoffman HM, Jones MC et al (2019) Partial Jacobsen syndrome phenotype in a patient with a de novo frameshift mutation in the ETS1 transcription factor. Cold Spring Harb Mol Case Stud 5(3):8. https://doi.org/10.1101/mcs.a004010

21 McDonald-McGinn DM, Sullivan KE, Marino B, Philip N, Swillen A, Vorstman JA et al (2015) 22q11.2 deletion syndrome. Nat Rev Dis Primers. 1:15071. https://doi.org/10.1038/nrdp.2015.71

22. Spaeder MC, Carson KA, Vricella LA, Alejo DE, Holmes KW (2011) Impact of the viral respiratory season on postoperative outcomes in children undergoing cardiac surgery. Pediatr Cardiol 32(6):801-806. https://doi. org/10.1007/s00246-011-9985-9

23. Li X, Wang X, Li S, Zeng M, Li D (2020) Viral respiratory infection, a risk in pediatric cardiac surgery: a propensity-matched analysis. Pediatr Crit Care Med 21(7):e431-e440. https://doi.org/10.1097/pcc.0000000000002308

24. Newburger PE, Dale DC (2013) Evaluation and management of patients with isolated neutropenia. Semin Hematol 50(3):198-206. https://doi.org/ 10.1053/j.seminhematol.2013.06.010

25. Dale DC, Welte K (2021) Neutropenia and neutrophilia. In: Kaushansky K, Prchal JT, Burns LJ, Lichtman MA, Levi M, Linch DC (eds) Williams hematology, 10e. McGraw Hill. https://accessmedicine.mhmedical.com/conte nt.aspx?bookid $=2962 \&$ sectionid $=252531041$

26 Hsieh MM, Everhart JE, Byrd-Holt DD, Tisdale JF, Rodgers GP (2007) Prevalence of neutropenia in the U.S. population: age, sex, smoking status, and ethnic differences. Ann Intern Med 146(7):486-92. https://doi.org/10. 7326/0003-4819-146-7-200704030-00004

27. Hamed E, Syed MA, Alemrayat BF, Tirmizi SHA, Alnuaimi AS (2021) Haemoglobin cut-off values for the diagnosis of anaemia in preschool-age children. Am J Blood Res 11(3):248-254

28. Anumudu C, Afolami M, Igwe C, Nwagwu M, Keshinro O (2008) Nutritional anaemia and malaria in pre-school and school age children. Ann Afr Med 7(1):11-17. https://doi.org/10.4103/1596-3519.55690

29. Zimmerman MS, Smith AGC, Sable CA, Echko MM, Wilner LB, Olsen HE et al (2020) Global, regional, and national burden of congenital heart disease, 1990-2017: a systematic analysis for the Global Burden of Disease Study 2017. Lancet Child Adolesc Health 4(3):185-200. https://doi.org/10. 1016/S2352-4642(19)30402-X

30. Zimmerman MS, Smith AG, Sable CA, Echko MM, Wilner LB, Olsen HE, Atalay HT, Awasthi A, Bhutta ZA, Boucher JL, Castro F (2020) Global, regional, and national burden of congenital heart disease, 1990-2017: a systematic analysis for the Global Burden of Disease Study 2017. Lancet Child Adolesc Health 4(3):185-200. https://doi.org/10.1016/s2352-4642(19)30402-x

31. Gilboa SM, Salemi JL, Nembhard WN, Fixler DE, Correa A (2010) Mortality resulting from congenital heart disease among children and adults in the United States, 1999 to 2006. Circulation 122(22):2254-2263. https://doi. org/10.1161/circulationaha.110.947002

32. Boneva RS, Botto LD, Moore CA, Yang Q, Correa A, Erickson JD (2001) Mortality associated with congenital heart defects in the United States. Circulation 103(19):2376-2381. https://doi.org/10.1161/01.CIR.103.19. 2376

33 Wu MH, Lu CW, Chen HC, Kao FY, Huang SK (2018) Adult congenital heart disease in a nationwide population 2000-2014: epidemiological trends, arrhythmia, and standardized mortality ratio. J Am Heart Assoc 7(4):e007907. https://doi.org/10.1161/JAHA.117.007907

34. Yu C, Moore BM, Kotchetkova I, Cordina RL, Celermajer DS (2018) Causes of death in a contemporary adult congenital heart disease cohort. Heart 104(20):1678-1682. https://doi.org/10.1136/heartjnl-2017-312777

35. Naidu P, Grigg L, Zentner D (2017) Mortality in adults with congenital heart disease. Int J Cardiol 245:125-130. https://doi.org/10.1016/j.ijcard. 2017.05.132

36. Diller G-P, Enders D, Lammers AE, Orwat S, Schmidt R, Radke RM et al (2021) Mortality and morbidity in patients with congenital heart disease hospitalised for viral pneumonia. Heart 107(13):1069. https://doi.org/10. 1136/heartjnl-2020-317706

37. Ghimire LV, Chou F-S, Moon-Grady AJ (2020) Impact of congenital heart disease on outcomes among pediatric patients hospitalized for influenza infection. BMC Pediatr 20(1):450. https://doi.org/10.1186/ s12887-020-02344-x

38. Soleimani A, Soleimani Z (2022) Presentation and outcome of congenital heart disease during Covid-19 pandemic: a review. Curr Probl Cardiol 47(1):100905. https://doi.org/10.1016/j.cpcardiol.2021.100905

39. Haiduc AA, Ogunjimi M, Shammus R, Mahmood S, Kutty R, Lotto A et al (2021) COVID-19 and congenital heart disease: an insight of pathophysiology and associated risks. Cardiol Young 31(2):233-240. https://doi.org/ $10.1017 /$ S1047951120003741

40 Yuki K, Koutsogiannaki S (2021) Neutrophil and T cell functions in patients with congenital heart diseases: a review. Pediatr Cardiol. https://doi.org/ 10.1007/s00246-021-02681-3

41. Sarwar S, Shabana Ehsan F, Tahir A, Jamil M, Shahid SU et al (2020) Hematological and demographic profile of Pakistani children with isolated ventricular septal defects (VSDs). Egypt J Med Hum Genet 21(1):36. https:// doi.org/10.1186/s43042-020-00079-z

42. Khalil A, Trehan R, Tiwari A, Malik R, Arora R (1994) Immunological profile in congenital heart disease. Indian Pediatr 31(3):295-300

43. Rhoden DK, Leatherbury L, Helman S, Gaffney M, Strong WB, Guill MF (1996) Abnormalities in lymphocyte populations in infants with neural crest cardiovascular defects. Pediatr Cardiol 17(3):143-149. https://doi. org/10.1007/bf02505203

44. Denic S, Narchi H, Al Mekaini LA, Al-Hammadi S, Al Jabri ON, Souid AK (2016) Prevalence of neutropenia in children by nationality. BMC Hematol 16:15. https://doi.org/10.1186/s12878-016-0054-8

45. Giglia TM, Massicotte MP, Tweddell JS, Barst RJ, Bauman M, Erickson CC et al (2013) Prevention and treatment of thrombosis in pediatric and congenital heart disease: a scientific statement from the American Heart Association. Circulation 128(24):2622-2703. https://doi.org/10.1161/01. cir.0000436140.77832.7a

46. Osthaus WA, Boethig D, Johanning K, Rahe-Meyer N, Theilmeier G, Breymann T et al (2008) Whole blood coagulation measured by modified thrombelastography (ROTEM) is impaired in infants with congenital heart diseases. Blood Coagul Fibrinolysis 19(3):220-225. https://doi.org/10. 1097/MBC.0b013e3282f54532

47. Sakazaki H, Niwa K, Echigo S, Akagi T, Nakazawa M (2007) Predictive factors for long-term prognosis in adults with cyanotic congenital heart disease_Japanese multi-center study. Int J Cardiol 120(1):72-78. https:// doi.org/10.1016/j.ijcard.2006.08.081

48. Lill MC, Perloff JK, Child JS (2006) Pathogenesis of thrombocytopenia in cyanotic congenital heart disease. Am J Cardiol 98(2):254-258. https:// doi.org/10.1016/j.amjcard.2006.01.083

49. Jensen AS, Johansson PI, Idorn L, Sørensen KE, Thilén U, Nagy E et al (2013) The haematocrit-an important factor causing impaired haemostasis in patients with cyanotic congenital heart disease. Int J Cardiol 167(4):1317-1321. https://doi.org/10.1016/j.ijcard.2012.03.181

50. Androne AS, Katz SD, Lund L, LaManca J, Hudaihed A, Hryniewicz Ket al (2003) Hemodilution is common in patients with advanced heart failure. Circulation 107(2):226-229. https://doi.org/10.1161/01.cir.0000052623.16194.80

51. Paul S, Paul RV (2004) Anemia in heart failure: implications, management, and outcomes. J Cardiovasc Nurs 19(6 Suppl):S57-66. https://doi.org/10. 1097/00005082-200411001-00008

52. Onur CB, Sipahi T, Tavil B, Karademir S, Yoney A (2003) Diagnosing iron deficiency in cyanotic heart disease. Indian J Pediatr 70(1):29-31. https:// doi.org/10.1007/bf02722740

53. Hågå P (1993) Normal hemoglobin levels in children with cyanotic heart disease. Is it iron deficiency anemia? Tidsskr Nor Laegeforen. 113(14):1710-1

54. Amoozgar H, Soltani M, Besharati A, Cheriki S (2011) Undiagnosed anemia in pediatric patients with congenital heart diseases: letter to the editor. Int Cardiovasc Res J 5(2):70-71. https://www.sid.ir/en/journal/ ViewPaper.aspx?id $=212876$

\section{Publisher's Note}

Springer Nature remains neutral with regard to jurisdictional claims in published maps and institutional affiliations. 